EESTI RAKENDUSLINGVISTIKA ÜHINGU AASTARAAMAT 1 (2004), 171-186

\title{
ISEORGANISEERUVAD KEELEELEMENDID EESTI KEELE EMOTSIOONISÕNAVARA NÄITEL
}

\author{
ENE VAINIK, TOOMAS KIRT
}

\begin{abstract}
Ülevaade. Artiklis lähtutakse ideest, et üks viis keeleelementide sisemist korda ja struktuuri avastada, on lasta neil ise organiseeruda. Eesti keele emotsioonisõnavara semantika uuringus oli eesmärgiks lahendada psühholoogiakirjanduses vastuolulisena ilmnenud emotsioonisõnavara universaalse struktuuri probleem. Iseorganiseeruvate kaartide meetodit kasutades jõuti tulemusele, et emotsioonisõnavara jaguneb kaheks kõrgema abstraktsioonitasemega jaotuseks: positiivseteks ja negatiivseteks mõisteteks. Positiivsus seostus uuritavatest tunnustest teotahte andmisega, meeldivusega, eelnemisega sündmusele, tunda olemisega kehas. Negatiivsus seostus ebameeldivusega, teotahte langusega, järgnemisega sündmusele ja tunda olemisega mõtetes. Psühholoogiateaduses saadavad vastuolulised tulemused (nn ringmudel vs. unipolaarne lahend) leiti taanduvat kasutatava metoodika ja algandmete spetsiifika mõjule. ${ }^{1}$
\end{abstract}

Võtmesõnad: leksikoloogia, semantika, psühholoogia, emotsioonisõnavara, iseorganiseerumine, semantilised tunnused

\section{Taustafilosoofiat}

Keel on protsess, milles dünaamiliselt põimuvad kaose ja korra elemendid. Tung keelenähtustest eelkõige korda ja ennustatavust otsida pärineb strukturalistlikust mõttevoolust. Keeleelementide mõnigi kord tuskatoovad kategoriseerimisprobleemid usutakse üldiselt lahenduvat, kui leitakse õigemad ja paremad liigitamise ja süstematiseerimise viisid. Küsimust on kaldutud nägema vaid kategoriseerimise protseduuride ning põhimõtete täiustamises. Keegi pole küsinud, kas keel üldse vajab mingisugust välist klassifitseerimist või keelenähtused ette ennustamist.

1 Artikkel on valminud ETF grandi nr 5040 osalisel toel. 
Kuidas küsida keelelt, kas ta soovib sisemiselt liigenduda, kuidas küsida keeleelementidelt, kas nad soovivad omavahel grupeeruda ja allianssi astuda? Üks võimalik vastus on proovida, mis juhtub, kui lasta keeleelementidel ise organiseeruda. Iseorganiseerumise ja mittelineaarse dünaamika mõiste pärineb üldisest süsteemiteooriast (nt Bertalanffy 1968) ning kaose filosoofiast (nt Bohm 1980), neid ideesid on edukalt rakendatud loodusteadustes, nüüd aga juba ka sotsiaalteadustes (nt organisatsioonikäitumise käsitlustes vt Wheatley 2002; psühhoteraapiakäsitlustes nt Butz jt 1998 ning sellesuunalisi lähenemisi on keeleteaduseski, nt Skousen 1989).

Kahekümnes sajand on arvutitehnoloogia näol andnud uued võimalused iseorganiseerumisprotsesside modelleerimiseks, üks variantidest on $\mathrm{nn}$ iseorganiseeruvate kaartide meetod (SOM) (vt Kohonen 2000), andmete reduktsioonimeetod, mis kasutab närvivõrgustiku analoogiat. Artiklis kirjeldatakse, mis juhtus, kui autorid lasid osal eesti keele emotsioonisõnavarast selle programmi abil ise organiseeruda, lähtudes tavakõnelejatest informantide poolt antud hinnangutest sõnade tähendustele.

\section{Uurimisprobleemi olemus}

Psühholoogiaalases kirjanduses valitseb juba aastaid vastuolu kahe koolkonna uurimistulemuste vahel, millest nn unipolaristid väidavad et 50$75 \%$ emotsiooninimetuste semantikast on kirjeldatav kahe mittevastandliku dimensiooni abil, milleks on üldise positiivse ja üldise negatiivse afekti faktorid (Watson, Tellegen 1985), ja nn bipolaristid väidavad, et emotsiooninimetuste semantikat esitab paremini ringmudel, mis moodustub kahest lõikuvast bipolaarsest (st vastandlike otstega) dimensioonist, milleks on meeldiv-ebameeldiv ning madal-kõrge aktivatsioon (Russell 1980).

Mõlemad koolkonnad on leidnud kinnitust paljude keelte andmetest, ja ka eesti keele emotsioonisõnad on demonstreerinud allumist mõlemale lähenemisviisile (Allik 1997, Allik, Realo 1997, Russell, Lewicka, Niit 1989, Kästik 2000). See tõik andis autoreile alust küsida, kas emotsioonisõnavara semantika väidetavalt universaalne, kuid jätkuvalt vastuolulisena ilmnev struktuur ei põhine mitte osaliselt psühholoogiauurimustes

$2 \quad \mathrm{SOM}=$ Self-Organizing Map. 
järjekindlalt kasutatavates andmeanalüüsi meetodites - faktoranalüüsis ja multidimensionaalses skaleerimises. Selle võimaluse kontrollimiseks pöördutigi SOM-ide kui eeldatavalt sõltumatu andmetöötlusmeetodi poole, mis laseb andmete sisemisel struktuuril iseorganiseerumise teel esile tulla.

Läbi viidud emotsioonisõnavara semantika empiirilise uuringu eesmärgiks oli leida eesti keeles edasi kantav kollektiivsete emotsiooniteadmiste struktuur ja testida valitud semantilise tunnuste kimbu relevantsust emotsioonisõnade tähenduste eristamisel selles mõisteruumi osas.

\section{Emotsioonisõnavara semantika uuring}

Aastal 2003 läbi viidud uurimuses vastas küsimustikule 100 katseisikut vanuses 14-76 aastat (keskmine iga 40,2), pooled vastanutest olid mehed ja pooled naised. Uuriti 24 emotsioone või emotsionaalseid seisundeid tähistava eesti keele sõna semantikat nende inimeste intuitsiooni ja teadmiste põhjal. Pilootuuringuga testiti mõõdetavate omaduseskaalade relevantsust, ülesannete sõnastuse arusaadavust ning jõukohasust tavaliste, ilma eriettevalmistuseta informantide jaoks.

Uuritavad sõnad olid valitud nii, et esindatud oleksid emotsioonide põhinimetused eesti keeles (viha, armastus, rõõm ja kurbus, vt Vainik 2002), kuid leiduks ka nende sõnade poolt tähistatavate emotsionaalsete seisundite kestuse ja intensiivsuse alusel oletatavasti eristatavaid astmeid (nt masendus, vaimustus, kirg, raev), eeldatavalt sotsiaalselt orienteeritud (nt kaastunne, kadedus) ja intrapersonaalseid tundeid (nt mõnu, ärevus), kognitiivsete protsessidega eeldatavalt seotud (nt pettumus, vaimustus) ja mitteseotud seisundeid (nt iha, mõnu). Võrdselt oli negatiivseid ja positiivseid emotsioonisõnu ning lisaks paar eeldatavalt indiferentset (nt üllatus, kaastunne).

Siinses artiklis vahendame esimese ülesande tulemusi, milles katsealustel paluti hinnata sõnade tähendust seitsmel 7-astmelisel skaalal omadustepaaride suhtes, kus kumbki skaala otstest esindas ühte näiliselt vastandlikest omadustest (tugev vs. nõrk tunne, kestuselt lühike vs. pikk, annab vs. võtab teotahet, tunda kehas vs. tunda mõtetes, oleneb ainult endast vs. oleneb rohkem teistest, meeldiv vs. ebameeldiv ning eelneb vs. järgneb sündmusele). 
Semantiliste diferentsiaalide meetodist (Osgood jt 1975) inspireeritud küsitlusmetoodikale omaselt sai mõlemat poolt hinnata väärtustega 1,2 ja 3. Kui kumbki tunnustest ei olnud küsitletute meelest oluline, sai vastaja valida skaala keskkoha ehk nulli. Selgitamaks vastandlike omaduste samaaegse esinemise võimalikkust või võimatust anti osalejatele võimalus märkida lisaks esimesele spontaansele hinnangule ka nn teine arvamus, mis sai hilisemas analüüsis arvesse võetud 0,5 väärtusega ja lahutatud esialgsest valikust. Hindamisskaalad miinus kolmest pluss kolmeni said töötlemise jaoks muudetud läbini positiivseteks skaaladeks ulatusega seitsmest üheni, kus 7 tähistas tugevamat, informantide poolt enamvalitud tunnust ja 1 selle vastandtunnuse selget avaldumist.

\section{Kuidas toimub iseorganiseerumine?}

Iseorganiseeruvad kaardid kujutavad endast edasisidega neurovõrku, mis kasutab valveta õppimise algoritmi ja läbi iseorganiseeruvuse protsessi kujundab väljundiks sisendandmete kaardistatud esitluse. Õppimisprotsess SOM-ides toimub järgmiselt. Sisendandmete hulgast võetakse juhuslikult üks näide ja kui seda näidatakse võrgule, siis väljundkihi sõlmed võistlevad omavahel, et saada "võitjaks". Võidab väljundkihi sõlmedest esitatud näitevektorile eukleidilise läheduse järgi kõige lähedasemaid kaale omav sõlm. Võitnud sõlme kaalud muudetakse sisendvektori kaalude suunas õpetamise mõju võrra.

Lisaks võitja kaaludele kohandatakse näitevektorile lähemale ka selle ümbruses asuvate sõlmede kaale. Kui kaart on algväärtustatud juhuslikult valitud kaalude väärtustega, siis väljundsõlmed korrastuvad kiiresti. Õpetamisprotsessi käigus ümbruse ulatus pidevalt väheneb, kuni muudetud saab ainult võitnud sõlm. Samuti kahaneb õpetamismõju õpetamisprotsessi käigus. Mõningates rakendustes väheneb õpetamismõju ka kauguse suurenedes võitnud sõlmest.

Õppimisprotsessi tulemusena koonduvad sarnased sisendvektorid rühmadesse. Mitmedimensioonilised sisendandmed esitatakse kahedimensioonilisel kaardil, kus sisendruumis lähedased vektorid on koondunud üksteise lähedusse. 


\section{Tulemused ja arutelu}

Uuritud emotsioonimõisted organiseerusid SOM-programmi abil kaardile (joonis 1), mis kujustab nendevahelist eukleidilist kaugust, kui kõik vahemaad on optimaalsed. Tumedamad alad kaardil tähistavad antud hinnangute suuremat erinevust. Üldine sõlmede paigutus osutus väljavenitatud ristküliku taoliseks, kusjuures mõisted ja mõistegrupid paigutusid kaardi äärtele 3 . Viimane asjaolu ilmutab "naabergruppide" suhtelist sarnasust ja üksteisest kaugel paiknevate mõistete suurt erinevust antud hinnangute alusel.

Joonis 1. Iseorganiseerunud emotsioonimõisted 7 omaduseskaala põhjal

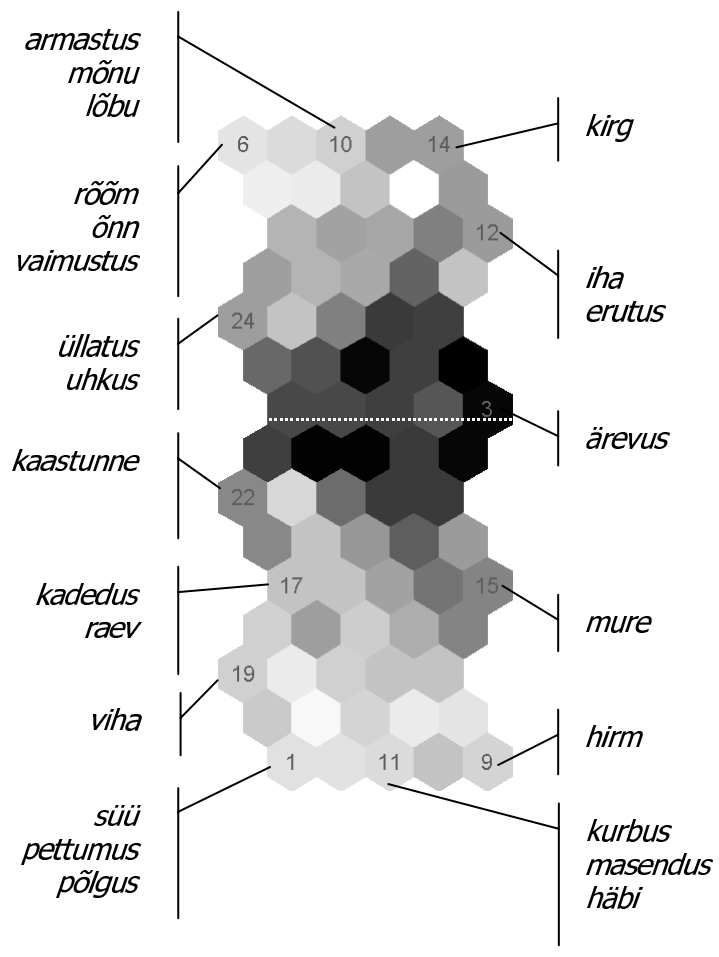

Kaartidel on programmi eripära tõttu emotsioonimõisted esitatud numbertähiste abil (vt tabel 1). Mitme mõiste paiknemisel kaardi samasse punkti kujutab programm neist vaid ühte, seepärast on kujutist vajadusel sõnasiltidega täiendatud. 
Selline tulemus iseorganiseeruva kaardi näol annab alust mitmesugusteks interpretatsioonideks. Kaardi väljavenitatus räägib selle kasuks, et üks domineeriv, võimalik, et üldise negatiivse ja positiivse afekti dimensioon, määrab enamuse emotsioonimõistete struktuurist, nagu on väitnud unipolaristid (Watson, Tellegen 1985), ovaalne paigutus kaardi servadesse toetab jällegi nn ringmudelit ja kahe bipolaarse dimensiooni teooriat (Russell 1985). Heleduse-tumeduse abil kujutatud nn kolmas mõõde kaardil lubab põhimõtteliselt tuge kirjanduses esitatud hüpoteetilisele kolmemõõtmelisele semantilisele ruumile, mille mõõtmeteks on hinnang, aktiivsus ja tugevus (Osgood, Suci, Tannenbaum 1975). Täie kindlusega ei kinnita ega lükka antud tulemus ümber ei bi- ega unipolaristide tulemusi. Tulemus räägib eelkõige erinevatest tõlgendusvõimalustest.

Mõistete paigutus kaardil on bilateraalselt sümmeetriline: negatiivsetele seisunditele osutavad sõnad paiknevad all ääres ja positiivsed ülal, vahepeale jääb üleminekupiirkond, kus asetsevad väljendumata või ambivalentsete hinnangutega mõisted (nt ärevus, üllatus, kaastunne). Kui püüda mõttes kaardil tumedusena kujutatud erisuste kuhjumist muuta distantsiks, siis on selge, et kaardi positiivne üla- ja negatiivne alaots paikneksid teineteise suhtes nurga all, mis erineks $180^{\circ}$-st. Selline mõtteeksperiment räägib mittevastanduvate dimensioonide kasuks.

Lisaks aine spetsiifikast johtuvale küllalt kergesti ennustatavale valdavale jaotusele positiivseteks ja negatiivseteks emotsioonisõnadeks huvitas autoreid, mis tegurid veel peale "hea ja kurja tundmise" mõjutavad emotsioonikategooria iseorganiseerumist. Seepärast vaadeldi lähemalt mõistete iseorganiseerumist uurimuses kasutatud hinnanguskaalade või semantiliste tunnuste kaupa. Eesmärk oli välja selgitada, millised valitud tunnustest on markeeritud ja millised distinktiivsed antud mõisteruumi osa jaoks, millised tunnused iseloomustavad emotsioonikategooria keskseid liikmeid eesti keeles.

Katses ühele skaalale paigutatud kahest näiliselt vastandlikust omadusest osutus üks emotsioonimõisteid kui semantilist välja tervikuna enam iseloomustavaks markeerimata tunnuseks. Emotsioon kui seesugune kaldub eestlastest informantide hinnangul olema pigem tugev kui nõrk, kestuselt pigem pikk kui lühike, kaldub pigem andma kui võtma teotahet, olema seotud pigem enda kui teistega, olema pigem ebameeldiv kui meeldiv ning pigem tunda mõtetes kui kehas. See markeerimata tunnustekomplekt kujundab üldise arusaamise "emotsioonist kui seesugusest" eesti 
Joonis 2. Distinktiivsed tunnused

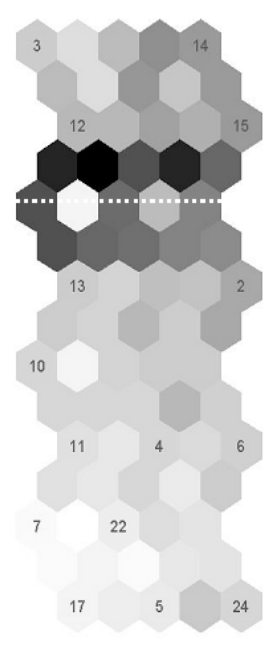

2.

järgneb ( $v s$. eelneb) sündmusele

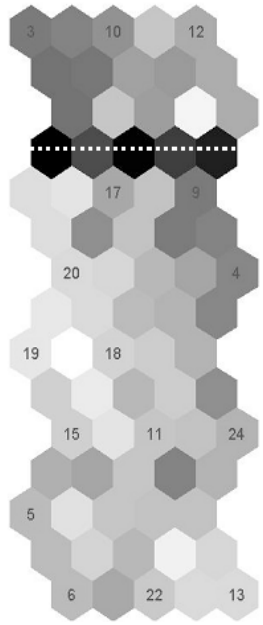

3.

tunda mõttes ( $v s$. kehas)

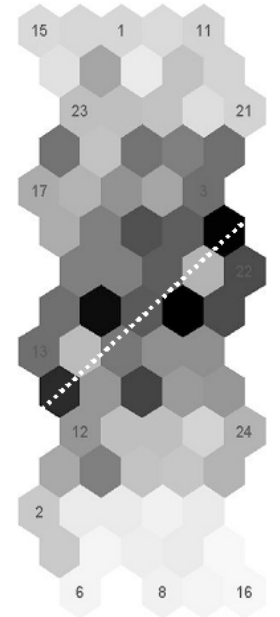

6.

annab (vs. võtab) teotahet

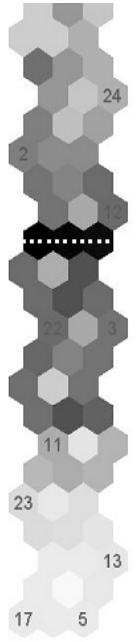

7.

ebameeldiv ( $v s$. meeldiv)

keeles. Eestlaste jaoks väidetavalt prototüüpne emotsioonimõiste viha (Vainik 2002b) näib kandvat just neid emotsioonikategooria tavaomadusi. Võimalik on ka vastupidine, et need omadused on viha kui emotsioonikategooria "parima esindaja" põhjal üldistatud kategooriale tervikuna (Vainik 2002b).

Mõned kasutatud tunnustepaaridest osutusid distinktiivseteks selles mõttes, et osalesid kõigi või enamuse uuritud mõistete kirjeldustes kõigi või enamuse keelejuhtide jaoks ning nende alusel toimus mõistete küllalt selge jagunemine markeeritud ja markeerimata tunnuseid kandvatesse mõistegruppidesse. Sellised tunnused olid ebameeldiv vs. meeldiv, annab vs. võtab teotahet, eelneb vs. järgneb sündmusele ja tunda mõtetes vs. kehas. Joonis 2 esitab 24 emotsioonimõiste paiknemise nende tunnuste alusel.

Sõnade paiknemine on näidatud numbertähistega (vt tabel 1), kuid olulisem kui üksiksõna asukoht, on praegu nende kaartide selge jagunemine kaheks piirkonnaks, millest alumises paiknevad valdavalt markeerimata tunnust kandvad mõisted ja tumedast alast ülevalpool valdavalt markeeritud tunnusega mõisted. Tunnuse olemasolu või esinemise määr 
muidugi varieerus informantide lõikes ja nii saame ka distinktiivtunnustest rääkida vaid tinglikult. Tegelikkuses on iga semantilise tunnuse olemasolu astme küsimus. Mõned neist kalduvad lihtsalt olema eri mõistete ja informantide lõikes selgemalt väljendunud.

Tabel 1. Uuritavad emotsioonisõnad ja nende numbertähised SOM esitustel

\begin{tabular}{cl|cl}
\hline Numbertähis & Sõna & Numbertähis & Sõna \\
\hline 1 & süü & 13 & kadedus \\
2 & uhkus & 14 & kirg \\
3 & ärevus & 15 & mure \\
4 & õnn & 16 & iha \\
5 & häbi & 17 & raev \\
6 & vaimustus & 18 & armastus \\
7 & masendus & 19 & viha \\
8 & rõom & 20 & lóbu \\
9 & hirm & 21 & pettumus \\
10 & mõnu & 22 & kaastunne \\
11 & kurbus & 23 & põlgus \\
12 & erutus & 24 & üllatus \\
\hline
\end{tabular}

Tabel 2. Omaduseskaalade omavahelised korrelatsioonid

\begin{tabular}{llcccccc}
\hline \multicolumn{1}{c}{ Liitskaala } & 1. & 2. & 3. & 4. & 5. & 6. & 7. \\
\hline 1. tugev (vs. nõrk) emotsioon & - & -.041 & -.028 & .253 & .032 & .157 & -.162 \\
2. järgneb (vs. eelneb) sündmusele & & - & .239 & -.008 & -.060 & -.079 & .121 \\
3. tunda pigem mõttes (vs. kehas) & & & - & .093 & .050 & -.031 & .122 \\
4. kestuselt pikk (vs. lühike) & & & & - & .137 & .034 & -.045 \\
5. oleneb ainult endast (vs. teistest) & & & & - & .002 & -.017 \\
6. annab (vs. vôtab) teotahet & & & & & - & -.720 \\
7. ebameeldiv (vs. meeldiv) & & & & & & & - \\
\hline
\end{tabular}

Märkus. Tugevamad korrelatsioonid kui $r=.2$ on esile tõstetud, $p=.05$ 
Joonis 3. Mittedistinktiivsed tunnused

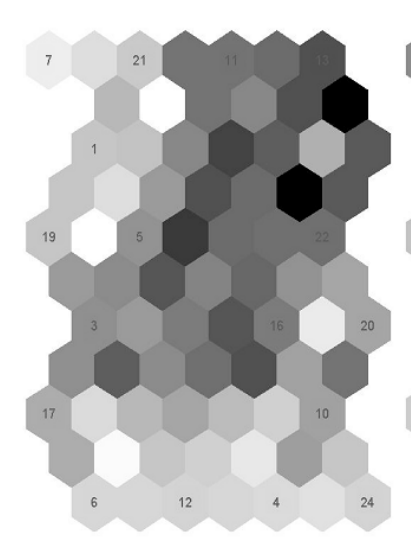

1.

tugev (vs. nõrk) emotsioon

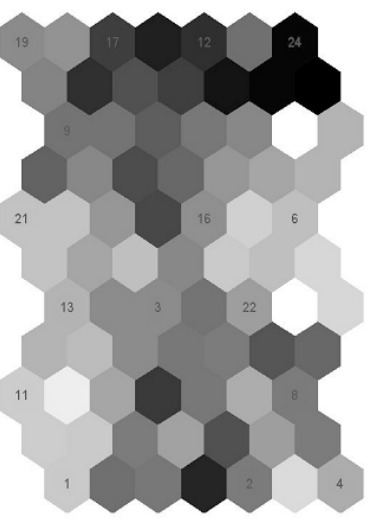

4.

kestuselt pikk ( $v s$, lühike)

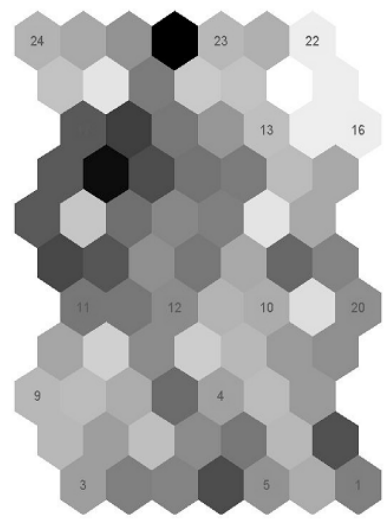

5.

oleneb ainult endast ( $v s$. teistest)

Tunnuste omavaheliste korrelatsioonide vaatlemine osutas (vt tabel 2), et nendest tunnustest ebameeldiv vs. meeldiv oli tugevalt negatiivselt seotud tunnusega annab vs. võtab teotahet $(r=-.720)$, st ebameeldivaks peetu ühtlasi võtab teotahet ja meeldivaks peetav üldiselt paneb tegusema. Tunnus järgneb vs. eelneb sündmusele korreleerus positiivselt tunda olemisega pigem mõtetes kui kehas $(r=.239)$, st mõtetes kaldutakse tundma olulisele sündmusele järgnevaid seisundeid ja kehatunded kalduvad olulisele sündmusele pigem eelnema.

Ülejäänud uuritud tunnusepaaridest ilmutasid vähest distinktiivsust mõistete ja/või suurt variatiivsust vastajate lõikes ning mõisted nende tunnuste põhjal organiseerunud SOM-kaartidel ei ilmutanud grupeerumist tunnuse markeerimatuse-markeerituse alusel (vt joonis 3 ).

Näiteks tunnus tugev osutus mittedistinktiivseks ja vaikimisi omaseks kõigile valitud mõistetele. Selline leid on kooskõlas kirjanduses leiduvate väidetega intensiivsusest kui emotsiooni prototüüpsuse peamisest kriteeriumist (Zammuner 1998; Niedenthal jt 2004). Suhteliselt tugevamaks hindasid keelejuhid siiski positiivseid emotsioone, mis nähtub jooniselt 3.1 paarisnumbritega tähistatud positiivsete mõistete paigutumisena üheskoos allapoole, kus hinnatud tugevuse aste on suurem. Emotsiooni hinnatud tugevus ilmutas lisaks positiivset korrelatsiooni (tabel 2, $r=.253$ ) teise kvantitatiivse näitaja - seisundi pikkusega, mis samuti ei osutunud 
kogu mõisteala mõttes distinktiivseks (vt joonis 3.4). Emotsioonide puhul ei näi tajutav intensiivsus tähendavat energiahulka ajaühiku kohta, vaid pigem hõlmatavat koguenergiat, mis pikema kestuse puhul on suurem.

Ka tunnus oleneb rohkem endast vs. teistest ei osutunud mõisteala liigendavaks distinktiivseks tunnuseks (joonis 3.5), kuid korreleerus mõningal määral seisundi tajutud pikkusega $(r=.137)$. Pikemaajalisi seisundeid (nt sü̈̈) kaldutakse rohkem pidama ainult endast olenevaks, samal ajal kui lühemaajaliste eest (nt raev, üllatus) peetakse vastutavaks peamiselt teisi.

Kogu mõisteala suhtes mittedistinktiivsed ja teineteist vastamisi mitte välistavad (unipolaarsed) tunnused ilmutasid suurt varieeruvust vastajate lõikes, kuid võivad sellegi poolest detailsemal käsitlusel osutuda relevantseks üksikmõistete struktuuris, eristades nt sisult lähedasi mõisteid omavahel või põhjustades polüseemiat ühe mõiste siseselt.

SOM-kaartide põhjal, mis kujutavad iga üksiku tunnusepaari panust emotsioonimõistete organiseerumisse (joonised 2 ja 3), tehti järeldus, et mõistete üldises organiseerumises (joonis 1) on nähtavasti suur panus hedooniliste hinnangute skaalal ebameeldiv vs. meeldiv, mis organiseeris mõisted tugevalt kaheks (joonis 2.7), venitades SOM-kaardi kuju ebaproportsionaalselt pikaks. Seega võiks hedoonilisi hinnanguid pidada skaalaks, mis põhjustas ühe dimensiooni domineerimise teise üle andmete esmasel iseorganiseerumisel (joonis 1).

Katseliselt proovisime lasta mõistetel organiseeruda ilma hedooniaskaalata. Tulemusena kogunesid mõisted nelja selgesti eristatavasse gruppi, mis on joonisel 4 piiratud kõverjoontega: negatiivsed emotsioonid, mida mõistetakse pigem järgnevana kui eelnevana olulisele sündmusele (nt masendus, kurbus, häbi, viha, raev kadedus), negatiivsed emotsioonid, mis pigem eelnevad fookussündmusele (nt hirm, mure, ärevus), fookussündmusele eelnevad positiivsed seisundid (sõnad iha, erutus, kirg) ja fookussündmusele järgnevana tajutud positiivsed seisundid ( $u h$ kus, rõõm, õnn, vaimustus, mõnu, lõbu).

Kuna hedooniaskaala oli eemaldatud, siis on selge, et piisab ka kuuest ülejäänud skaalast, et mõisted jaguneksid positiivseteks ja negatiivseteks. See tinglik jaotus on kujutatud joonisel valge punktiirjoonega. Positiivsuse ja negatiivsuse suhtes ambivalentseks osutusid mõisted kaastunne ja üllatus, mille puhul vastajate hinnangud on olnud vastuolulised ja varieeruvad või selgesti väljendumata. See tulemus sobib hästi kokku uurija 
Joonis 4. 24 emotsioonisõna paigutus hedooniahinnanguteta

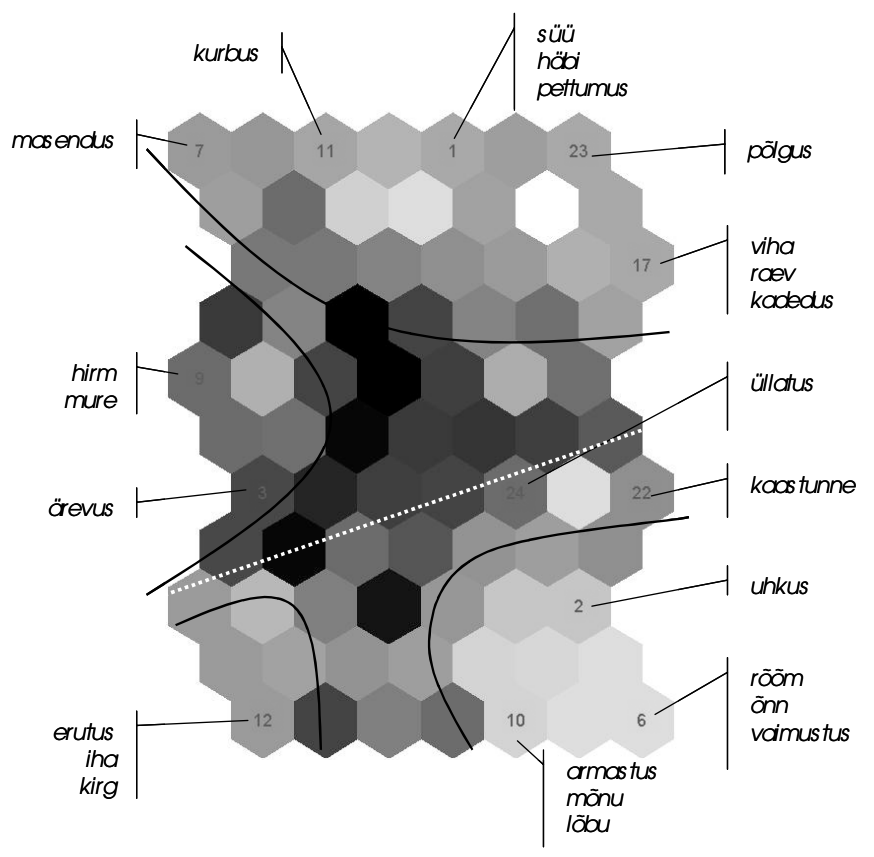

intuitsiooniga, mis ütleb, et üllatus võib olla nii meeldiv kui ebameeldiv ja et kaastunne, kuigi moraalselt kõrgelt väärtustatud, ei pruugi tundena olla siiski kuigi positiivne, sest kellelgi on esmalt pidanud minema halvasti. Grupeerunud sõnade tähenduse alusel saab väita, et selle SOM-kaardi varjatud dimensioonideks on suure tõenäosusega seisundit fookussündmuse suhtes orienteeriv skaala järgneb vs. eelneb sündmusele ja motivatsiooniliste hinnangute skaala annab vs. võtab teotahet.

Kuna ka hedooniaskaalat arvesse võtmata koondusid mõisted tähenduslikult sarnastesse gruppidesse, ainult et harmoonilisemalt, üldist kujutist deformeerimata, siis tegime järelduse, et emotsioonisõnade semantikas sisalduvad emotsioonide positiivsus- ja negatiivsushinnangud on kõrgema tasemega abstraktsioonid, mis sünnivad teiste semantiliste tunnuste omavahelise koostoime põhjal. Tunnuste omavahelistest korrelatsioonidest (vt tabel 2) selgus, et negatiivsus seostub ebameeldivusega, teotahte langusega, seisundi järgnemisega sündmusele, tunde nõrkusega ja tunda olemisega mõtetes; positiivsus seostub meeldivusega, teotahte suurenemisega, tunde tugevusega, eelnemisega sündmusele ja tunda olemisega kehas. Kaudselt on negatiivsuse-positiivsusega seotud ka ülejäänud 
tunnused, ainult et mittedistinktiivse tunnuse tugevus kaudu, mis seostub positiivselt pikkusega ja viimane omakorda olenemisega ainult endast.

Hedooniliste hinnangute skaala toimib nagu mitmemõõtmelise semantilise ruumi näiline projektsioon ühele mõõtmele. Meeldib-ei meeldi on arvatavasti evolutsiooni käigus kujunenud kiire ja prekontseptuaalne kahevalentne viis otsustada iga sündmuse kasulikkuse ja kahjulikkuse üle isikule ja tema eeldatavale teovõimele antud olukorras (Vainik 2004). Tegemist on nn esimese astme emotsiooniteadmistele omase struktuuriga (Planal, Fitness 1999).

Näiline on see projektsioon ka selles mõttes, et tegelikkuses võib olla tegu ajalooliselt hoopis vastupidise protsessiga: mitmemõõtmeline semantiline ruum oma dimensioonidega on emotsiooniteadmiste struktuuris võetud kasutusele selleks, et interpreteerida organismi toimimisest saadavat primitiivset positiivset ja negatiivset tagasisidet (Vainik 2004). Viimane tõlgendus on kooskõlas kirjanduses esitatud seisukohaga, et inimteadvus kui selline on evolutsiooni käigus kujunenud seoses eelistega, mida on andnud emotsioonide tundmise äratundmine ja interpreteerimine seoses asetleidvate intra- ja interpersonaalsete sündmustega (Damasio 1999).

\section{Kokkuvõtteks}

Emotsiooniteadmiste struktuuri bi- ja unipolaristlike seletuste vastuolu kirjanduses on osalt seletatav eri koolkondades kasutatavate lähteandmete ja statistiliste mudelite erisusega. Enesekohaste hinnangute tulemused töödelduna faktoranalüüsiga kalduvad tulemuseks andma unipolaarset struktuuri ja sõnasarnasuse hinnangute tulemused töödelduna multidimensionaalse skaleerimisega kalduvad andma tulemuseks ristuvate vastanduvate dimensioonidega ringmudelit. Iseorganiseeruvate kaartide meetod näitas andmete mitmetitõlgendatavust ja võimaldas lähemalt vaadelda üksikute tunnusepaaride panust emotsioonimõistete üldise valentsi kujunemisse.

Artikli autorid on seisukohal, et üldise positiivsuse faktorit ei peaks samastama meeldivushinnanguga ja üldise negatiivsuse faktorit lihtsalt ebameeldivusega. Väidame eelpool esitatud uurimistulemuste põhjal, et emotsioonimõistete üldises valentsis toimivad koos omavahel tugevalt negatiivselt korreleeritud hedoonilised ja motivatsioonilised hinnangud ja 
et üldist positiivsust võiks samastada pigem teotahte tõusuga ja üldist negatiivsust ebameeldivusega. Niiviisi mõistetud positiivsus ja negatiivsus ei välista teineteist, mida on näha ka mõnede mõistete struktuurist, mis ebameeldivusele vaatamata olid hinnatud mõõdukalt teotahet andvateks (nt viha, raev, kadedus) või mida teotahte andmisest olenemata ei hinnatud eriti meeldivatena (nt iha). Ka kirjanduses väljatoodud mõisteline tühik eesti keeles madala aktivatsiooniga positiivsete seisundite jaoks (Kästik 2000) seletub tendentsiga tõlgendada positiivsena pigem teotahet andvaid ja kõrgema aktivatsiooniga seisundeid. Madal aktivatsioon seostub teovõimetusega, mida kaldutakse hindama negatiivsena.

Emotsioonimõistete teotahtega samastatud positiivsus ja ebameeldivusega samastatud negatiivsus ei ole sellised vastandid nagu ühe ja sama skaala diametraalselt eri otsad. Tegemist on eraldi skaaladega, mis toimivad koos ja enamasti erisuunaliselt ning loovad sellega aluse emotsioonide vastandamisele mõistelisel tasandil ning emotsiooninimetuste antonüümiale leksikonis.

\section{Lõpetuseks}

On põhjust oletada, et nn kaose piiril toimuvatel iseorganiseerimisprotsessidel on ka keelenähtuste tekkes, kujunemises ja dünaamikas suurem roll, kui seni on üldiselt osatud või tahetud mõelda. Käesolevas artiklis kirjeldatud närvivõrku modelleeriva meetodiga läbi viidud eksperimendid üritavad olla vaid katseks esitleda ühte alternatiivset viisi keelenähtuste käsitlemiseks, mis kaost aktsepteerivast taustafilosoofiast välja võib kasvada. Ja keegi ei tea, millega see kõik veel ükskord lõpeb.

\section{Kirjandus}

Allik, J. 1997. Psühholoogia lihtsusest. Tartu: Tartu Ülikooli Kirjastus.

Allik, J. \& Realo, A. 1997. Emotional experience and its relation to the Five-Factor Model in Estonian. - Journal of Personality 65 (3), 625-645.

Bertalanffy, L. 1968. General System Theory: Foundations, Development, Applications. New York: Braziller.

Bohm, D. 1980. Wholeness and the Implicate Order. New York: Ark.

Butz, M. R. \& Carlson, J. M. \& Carlson, Jon 1998. Chaos theory: Self-organization and symbolic representation in family systems. - Family Journal 6 (2), 106-126. 
Damasio, A. R. 1999. The Feeling of What Happens. Body and Emotion in the Making of Consciousness. New York, San Diego, London: Harcourt Brace \& Company.

Kohonen T. 2000. Self-organizing Maps. 3. trükk. Berlin: Springer.

Kästik, L. 2000. Emotsioone väljendavate terminite subjektiivne ruum. Diplomitöö Tallinna Pedagoogikaülikoolis.

Niedenthal, P. M. \& Auxiette, C. \& Nugier, A. \& Dalle, N. \& Bonin, P. \& Fayol, M. 2004. A prototype analysis of the French category "émotion". - Cognition \& Emotion 18 (3), 289-312.

Osgood, C. E. \& Suci, G. J. \& Tannenbaum, P. H. 1975. The Measurement of Meaning. Urbana and Chicago: University of Illinois Press.

Planalp, S. \& Fitness, J. 1999. Thinking/feeling about social and personal relationships. - Journal of Social and Personal Relationships 16 (6), 731-750.

Russell, J. A. 1980. A circumflex model of affect. - Journal of Personality and Social Psychology 39, 1161-1178.

Russell, J. A. \& Lewicka, M. \& Niit, T. 1989. A cross-cultural study of a circumflex model of affect. - Journal of Personality and Social Psychology 57 (5), 848856.

Skousen R. 1989. Analogical Modelling of Language. Dordrecht: Kluwer Academic.

Zammuner, V. L. 1998. Concepts of emotion: "Emotionness", and dimensional ratings of Italian emotion words. - Cognition and Emotion 12 (2), 243-272.

Vainik, E. 2002a. Emotions, emotion terms and emotion concepts in an Estonian folk model. - Trames 6 (4), 322-341.

Vainik, E. 2002b. Kas eestlased on "kuumaverelised"? Eestlaste rahvalikust emotsioonikategooriast. - Emakeele Seltsi aastaraamat 47 (2001). Tallinn, 63-86.

Vainik, E. 2004. Lexical knowledge of emotions: The structure, variability and semantics of the Estonian emotion vocabulary. Dissertationes Linguisticae Universitatis Tartuensis 5. Tartu: Tartu University Press.

Watson, D. \& Tellegen, A. 1985. Toward a consensual structure of mood. - Psychological Bulletin 98, 219-235.

Wheatley M. J. 2002. Juhtimine ja loodusteadus: korra otsingul kaootilises maailmas. Tartu: Fontese Kirjastus. 


\section{ENE VAINIK, TOOMAS KIRT. ISEORGANISEERUVAD KEELEELEMENDID .. \\ The self-organizing elements of language: the case study of the Estonian emotion terms}

ENE VAINIK, TOOMAS KIRT

In the present article it was claimed that one way to study the inherent structure of language and its elements is to use a self-organizing approach. In the reported study the method of self-organizing maps (SOM) was applied on the semantic data of Estonian emotion terms. One hundred informants had filled in the questionnaires about the presence and measure of seven specific semantic features in different emotion concepts. The purpose of the task was to find out about the reasons of the main controversy the matter of the proposed universal structure of the emotion lexicons has been handled in the psychological literature so far.

As a result the self-organizing algorithm of the program generated a topological map of Estonian emotion terms that demonstrated a clear division of the concepts into two bilaterally symmetric clusters: positive and negative emotion terms. This kind of structure is in accord with the findings of the universal structure of the emotion lexicons in the psychological literature. The discussion is about whether the positivity and negativity should be treated as unipolar (and not mutually exclusive) dimensions or as the opposite ends of one bipolar dimension acting together with a crossing dimension of general activation.

The role of the single features co acting in the generation of the selforganizing map were further investigated and discussed. It was found that four of the seven features were distinctive by nature causing the set of selected emotion terms to cluster clearly into two subsets (unpleasant vs. pleasant, increases vs. decreases action readiness, follows vs. precedes the event, felt in the mind vs. body). Three of the selected features were found to be indistinctive (strong vs. weak emotion, long vs. short in duration, depends mostly on oneself vs. others). The scale of hedonistic evaluations (pleasant vs. unpleasant) was suspected to act as a higher order abstraction among the specific evaluations given on the other scales, as it caused a far stronger division of the concepts, even extending the self-organizing map in one direction. It was concluded from the analyses that it might be reasonable to interpret the overall negativity of emotion terms as the unpleasantness of the referred states and the general 
positivity as the capacity of the referred state to increase one's action readiness. In that way the controversy of the psychological literature will be resolved.

It was further hypothesized in the end of the article that the hedonistic dualism of the emotion concepts could be understood as a projection of the evolutionary primary two-valenced evaluations on to the multiplicity of contexts and situations presented in the specific semantic content of every single emotion term. The contrary is also possible: the additional semantic features and distinctions in the situations and contexts have been added in the history of human cognition to interpret and to learn better form the two-valenced primitive feedback given by automatic hedonisticmotivational evaluations.

The self-organizing approach to emotion terms demonstrated the possibility of multiple interpretations and confirmed the suspicion that controversial results of different schools in psychology might easily be a result of applied methodologies and statistical methods.

ENE VAINIK (1964) töötab Eesti Keele Instituudi leksikoloogiasektoris vanemteadurina. On lõpetanud Tartu ülikooli eesti keele eriala aastal 1989. a, psühholoogiaõpingud aastail 1997-2000, magistrikraad üldkeeleteaduses aastast 2001 ja doktor samal alal aastast 2004. Huvi- ja uurimisalaks on läbi aastate olnud semantika ning keele ja psühholoogiliste nähtuste lõikumisala inimteadmistes ning käitumises. Teemad on olnud seotud hinnangulise suhtlusleksikaga, kognitiivse grammatikaga (väliskohakäänded), semantiliste suhetega õigussõnavaras. Emotsioonisõnavara temaatikaga tegeleb aastast 2001.

ene@eki.ee

TOOMAS KIRT (1971) töötab Finantsinspektsioonis IT audiitorina. 1999. aastal omandas Tallinna Tehnikaülikoolis tehnikamagistri kraadi (magistritöö "Iseorganiseeruvad kaardid panganduses"). Alates 1999. aastast tegeleb Tallinna Tehnikaülikoolis doktorikraadi omandamisega. 2001. aasta kevadsemestril õppis Helsingi Tehnikaülikoolis.

Uurimisteemadeks iseorganiseerumine, andmeanalüüs ja tehisintellekt.

Toomas.Kirt@mail.ee 